\title{
LA EPISTOLA SOSAE AD SODALES DE JUAN DE IRIARTE Y EL GÉNERO DE LA EPÍSTOLA POÉTICA EN EL SIGLO XVIII
}

\author{
María Ruiz Sánchez \\ Universidad de Murcia \\ mrs4@um.es
}

\begin{abstract}
RESUMEN
En este artículo se estudia un poema de Juan de Iriarte, la Epistola Sosae ad sodales. Se trata de una obra de juventud del autor, que debe ser interpretada a la luz de la concepción de los géneros literarios propios de la época, especialmente de la heroida y la elegía. La heroida, entendida como epístola heroica, estaba plenamente aclimatada como género literario en las literaturas modernas y poseía rasgos que la aproximaban a la elegía, pero también otros que la singularizaban.
\end{abstract}

PALABRAS ClAVE: Iriarte, poesía neolatina, elegía, heroida, epístola poética.

THE EPISTOLA SOSAE AD SODALES BY JUAN DE IRIARTE

AND THE GENRE OF THE POETIC EPISTLE IN THE $18^{\text {TH }}$ CENTURY

\section{ABSTRACT}

In this paper a poem by Juan de Iriarte, the Epistola Sosae ad sodales is studied. It is a piece from the writer's youth, which must be interpreted in the light of the concept of the typical literary genres of the era, especially that of the heroides and the elegy. The heroides, understood as being a heroic epistle, was fully acclimatized as literary genre in modern literature and it had features that associated it with elegy, but also others that singled it out.

KEY WORDS: Iriarte, Neolatin poetry, elegy, heroide, poetic epistle.

\section{LA OBRA DE JUAN DE IRIARTE}

La actividad profesional de Juan de Iriarte y Cisneros (1702-1771) abarcó prácticamente todas las disciplinas relacionadas con el mundo literario. Entre los muchos escritos que ha dejado son raros los documentos relativos a su persona ${ }^{1}$. En 1713 con once años lo envió su padre a Francia para completar su educación. Allí asistió a colegios de la Compañía de Jesús y adquirió una formación que dejaría una profunda huella en su devenir profesional e intelectual. En el año 1724 se instaló en Madrid donde iría abriéndose camino hasta llegar a ser bibliotecario de la Biblioteca Real, oficial traductor de la Primera Secretaría de Estado y del Despacho, 
miembro de la Real Academia Española y académico honorario de la Real Academia de Bellas Artes de San Fernando.

La contribución más importante de Iriarte como helenista fue la publicación en 1769 de Regiae Bibliothecae Matritensis Codices Graeci Mss., obra en la que se estudian y describen unos 125 códices de los 230 que figuraban en la Biblioteca Real². El despertar de una corriente protohelénica durante el siglo XVIII favoreció esta empresa (Salas Salgado, 1998b: 710).

La obra de Iriarte más conocida hoy para los latinistas es su Gramática latina escrita con nuevo método y nuevas observaciones, en verso castellano con su explicación en prosa, que se publicó en $1771^{3}$.

El discurso Sobre la imperfección de los diccionarios, leído en la Real Academia el 10 de marzo de 1750 (Iriarte, 1774: 335-348, II), constituye, junto con sus trabajos como director del Diccionario Latino-Castellano y Castellano-Latino, su principal contribución a la lexicografía

Conservamos algunos textos poéticos de Iriarte que fueron publicados en vida del autor. Fuera de estas composiciones, nuestra principal fuente de conocimiento de las obras de Iriarte es la edición póstuma de Obras sueltas (en lo sucesivo OS) realizada por los sobrinos del autor en $1774^{5}$. También poseemos en el

${ }^{1}$ La mayoría de datos sobre su vida y obra los conocemos gracias a la Noticia de la vida $y$ literatura de D. Juan de Iriarte, impresa al frente de la primera edición de su Gramática latina (1771) y repetida después, con algunas modificaciones, en las Obras sueltas de D. Juan de Iriarte (1774). Esta Noticia fue escrita por su sobrino Bernardo de Iriarte basándose en unas memorias incompletas conservadas en el manuscrito B99-A-10(2) (pp. 155-170). Las comenzó el 20 de enero de 1762 y solo abarcan sus primeros años de vida, sin que al parecer llegara a concluirlas. Las biografías existentes sobre Juan de Iriarte son en su mayoría extractos de esas obras. Cf. Viera y Clavijo (1783: 584-588), Sempere y Guarinos (1789: 181-190) y Cotarelo y Mori (1897).

${ }^{2}$ El jesuita Tomás Serrano dedicó un admirativo epigrama a la obra de Iriarte, II, 20, Ad Joannem Iriartem qui in Regia Matritensi Biblioteca plura Graeca detexit antehac inedita (Serrano, 1788: 77).

${ }^{3}$ Cf. para una visión general del contenido de la Gramática Cuyás de Torres (1992) y para otros aspectos Plaza Picón (2004), Tubau (2004), Hernández González (1996) y Cuyás de Torres (1996b, 2002, 2005a y 2005b). En relación con la métrica cf. Cuyás de Torres (1996a: 44).

${ }^{4}$ Sobre la faceta de Iriarte como lexicógrafo pueden consultarse los trabajos de Santana Henríquez (1990) y Hernández González (1988-1989). Lo relativo al Diccionario Latino-Castellano se halla explicado en la Noticia de la vida y literatura de D. Juan de Iriarte, que sirve de introducción a las Obras sueltas y a la Gramática latina (Iriarte, 1771: 17-19) y en dos cartas de Iriarte al conde de Valparaíso y una de Juan de Santander, bibliotecario mayor, al marqués de Esquilache (Ochoa, 1870: 194-199).

${ }^{5}$ Obras sueltas de D. Juan de Iriarte, publicadas en obsequio de la literatura, a expensas de varios caballeros amantes del ingenio y del mérito (1774). El tomo I contiene epigramas profanos y sagrados, traducciones de epigramas ajenos, epigramas castellanos, traducciones de epigramas de Marcial, poemas profanos y sagrados e inscripciones latinas; el tomo II, refranes castellanos traducidos en verso latino, obras varias de elocuencia y obras varias de crítica. La obra poética de Juan de Iriarte ha sido objeto de nuestra tesis doctoral, defendida en la Universidad de Murcia en 2014. Para la concepción del género epigramático en Juan de Iriarte y los epigramas en general puede consultarse Ruiz Sánchez 
"Fondo Iriarte" en la Fundación B. March de Palma de Mallorca los manuscritos del autor en los que se basó la edición póstuma ${ }^{6}$.

\section{LA EPISTOLA SOSAE AD SODALES}

En el tomo I de OS la poesía de Iriarte está dividida en dos secciones principales: los epigramas y los poemata. Estos últimos comprenden todos los textos más extensos. Entre ellos se encuentra el poema titulado Epistola Sosae ad sodales (OS: 451-454, I).

\section{Epistola Sosae ad sodales \\ Cuius Auctor personam induit.}

O mihi plus uita cari, pia turba, Sodales,

Quo caret, en uobis mittit amicus aue:

Mittit amicus aue, cui uiuere summa malorum est,

Et cui mille neces non peperere necem.

Mittit ab extremo terrarum littore Sosa,

Ludibrium terrae, ludibriumque maris.

Non tamen hic aliquam libet implorare medelam;

Mors erit una meis nempe medela malis.

At nostri precor heu! miserescite; nec mihi fletus

(Sors rogat hoc unum nostra) negate, precor.

Littore ab Eoo uentos sortita fauentes,

Nostra per aequoreas iam ratis ibat aquas.

Hic aurum, hic spes, hic omni pretiosior auro

Uxor, et Uxoris pignora cara meae.

Et medium iam nauis iter secura tenebat,

Signaque iam nostrae pene salutis erant,

Cum subito, proh instabilis fallacia ponti!

Incubuit toto dira procella mari.

Protinus iratis agitatus inhorruit undis

(2008, 2015a, 2015b, 2015c, 2016a, 2016b y 2017) y Cuyás de Torres (2010). Para las traducciones de los epigramas de Marcial véase Cuyás de Torres (1989 y 2009). Para las inscripciones latinas véase Cuyás de Torres (2014). Sobre los refranes puede consultarse Gete (1999). Entre los trabajos de Iriarte como crítico destaca el referente al libro IV de la Poética de Ignacio de Luzán (OS: 475-509, II), que trata sobre el poema épico, así como la crítica de la versión castellana de las Obras de Ovidio por Diego Suárez de Figueroa. Sobre este último tema puede consultarse Salas Salgado (1998a y 2007).

${ }^{6}$ Para todo lo relacionado con la historia de la formación del "Fondo Iriarte" véase De Andrés (1986: 601). 
Pontus, et immanes tollit ad astra minas.

Obruit unda ratem, spoliisque animosa superbis,

Captiuas uictrix uoluere gaudet opes.

At nos, in tanto nobis spes unica fato,

Excipit alueolo proxima cymba suo.

Quo nos uentus agit, quo nos rapit impetus undae,

Huc trahimur rabido praeda uoranda mari.

Tellurem appulimus tandem; sed barbara tellus,

Barbariorque ipsis fluctibus illa fuit.

Terra inculta, informis, inops, terra horrida, nudis

Rupibus, et uastis uix adeunda iugis.

Ergo meis cinctus, quibus unda pepercerat, armis,

Desertam lustro naufragus hospes humum;

Siquas Uxori Natisque gementibus escas

Obuia syluestri praebeat arbor agro.

Ecce uirum gens torua ruit, uultuque ferino

Aspera fata minans, ponere tela iubet.

Ter uolui medios irrumpere solus in hostes,

Optatamque diu sponte subire necem:

Ter temerata manus, mediis ter destitit ausis:

Vicit amor: uictor ponere tela iubet.

Scilicet et Coniux stratique in littore Nati

Fraenabant animum, uincula blanda, meum.

Arma cadunt: solis armatus fletibus ora,

Exiguos uultu supplice posco cibos.

Ast illi duro uultu irrisere precantem,

Surdaque praecipiti terga dedere fugae.

Ergo tristis, inops, spoliatus, inermis et amens

Infausto repeto littora cara gradu.

Hei mihi! Quid uideo? Natos animam exhalantes

Obiiciunt oculis littora moesta meis.

Heu! quos tunc habui Patris sub pectore sensus!

Quos qui dimidio corpore uiuit, habet!

Una superstes erat, sobolis post funera, Coniux:

Substulit hanc etiam mixta dolore fames.

Quid faciam sine prole Pater, sine Coniuge Coniux,

Solaque de sociis pars ego uiua meis?

Pabula sunt lacrymae; sunt littora nuda cubile;

Voxque necem, usque necem triste gemendo uocat.

Vos autem exsequias mihi iam persoluite, Amici:

Iam mihi funereas fundite, quaeso, preces.

Tot nostris passum mortalia uulnera membris,

Mors ni certa fame, certa dolore manet.

Para llevar a cabo la edición de $O S$, los sobrinos se basaron en los manuscritos de su tío, cuyo examen nos permite una comprensión más profunda del texto. 
El poema de Sousa está en el manuscrito B102-A-14, que recoge composiciones de la juventud de Iriarte en París, entre los años 1715 y $1723^{7}$.

Este manuscrito, que lleva el encabezamiento Versos latinos míos de cuando yo estudiaba en París, conserva muchos textos desechados posteriormente por el autor. Son probablemente los intentos poéticos más antiguos de Iriarte. En este cuaderno se mezclan indiferentemente epigramas y poemata. Tanto unos como otros tienen el aire de piezas un tanto artificiales, no lejos de lo que podrían ser los ejercicios escolares avanzados sobre un tema propuesto previamente . $^{8}$

El hecho singular de haber conservado el fondo manuscrito de las obras producidas por Iriarte supone una oportunidad, casi única en el campo de la filología clásica, para estudiar los mecanismos de escritura y de creación de una obra literaria.

El texto de $O S$ es prácticamente idéntico al que ofrece el manuscrito. Al tratarse de materiales heterogéneos en el manuscrito el poema de Sousa ocupa las páginas 13, 14 y 17. En las páginas 13 y 14 hay en total 44 versos, 22 en cada una. En la página 15 están los epigramas De Danubio uariae religionis regiones alluente y Quid Bachus occupet pedes? En la página 16 se encuentra el poema Astrologus in puteum cadens y la página 17 continúa de nuevo con el poema de Sousa que ha dejado interrumpido antes. Se inicia con el verso 45 y sigue hasta el final. En total son 62 versos.

En el texto del manuscrito pueden leerse algunas variantes procedentes de la fase de redacción que han sido descartadas y tachadas por el propio autor. Han sido escritas al mismo tiempo que las que han quedado como definitivas, con el mismo tipo de letra y con la misma tinta".

Solo hay una corrección editorial, con otra letra diferente, que no proviene del autor y contribuye a mejorar la legibilidad de las palabras Voxque en el verso 58. Tachado se lee también con la misma letra de todo el poema Voxque. Proviene igualmente de los editores la aclaración añadida al título: Cuius Auctor personam induit.

Enumeramos a continuación las correcciones de la epístola en el citado manuscrito:

- v. 29: tachado praerupta después de inops, luego ha escrito (con la misma tinta y letra) terra horrida nudis, que da sentido, pero crea una repetición poco deseable de terra.

- v. 51: tachado se lee Quos heu, que ha sido substituido por Heu quos.

${ }^{7}$ Para la descripción del manuscrito véase Salas Salgado (1999 y 2006).

${ }^{8}$ En el mismo manuscrito B102-A-14 se encuentran también los poemata Hercules Pygmaeorum uictor (pp. 18-19), la fábula del astrólogo que cayó al pozo, Astrologus in puteum cadens (p. 16), el poema sobre la muerte de Aristóteles, Mors Aristotelis (pp. 19-20), o el poema sacro Pueri in Fornace (pp. 42-44). Un estudio comparativo entre la edición impresa del poema Hercules Pygmaeorum y la que figura en el manuscrito puede verse en Salas Salgado (2002).

${ }^{9}$ La crítica genética distingue cuatro fases en el proceso de escritura: pre-redaccional, redaccional, pre-editorial y editorial (De Biasi-Wassenaar, 1996). Con respecto a la crítica genética puede verse nuestra tesis doctoral (Ruiz Sánchez, 2014: 3-12). 
- v. 52: uiuit es corrección de una palabra tachada e ilegible.

- v. 59: tachado se lee nobis. La variante definitiva es Mihi iam (con la misma letra y tinta).

- $\quad$ vv. 61-62: en una primera redacción ha escrito Me mors certa manet post tot... Luego lo ha tachado y lo ha substituido por Tot nostris passum mortalia. Es, por tanto, corrección (con la misma letra y tinta), escribiendo el resto de verso un poco más arriba para enlazar con la corrección. En el inicio del pentámetro parece leerse Si non, que ha sido substituido por Mors ni.

\section{TRADUCCIÓN}

El poema trata de un episodio trágico, el naufragio de unos viajeros portugueses a su regreso de Oriente. El hablante es el propio personaje. La traducción que proponemos del texto es la siguiente ${ }^{10}$ :

Oh camaradas, piadosa multitud, más queridos para mí que la vida, vuestro amigo os envía la salud de la que carece. Os envía salud el amigo, para el que vivir es la suma de los males y a quien mil muertes no han causado la muerte. Os la envía desde una costa que se encuentra en el confín de las tierras, Sousa, juguete de la tierra y del mar. No quiero, sin embargo, implorar remedio alguno. La muerte será en verdad el único remedio a mis males. Pero compadeceos, os lo suplico, de mí; y no me neguéis, os lo suplico (esto es lo único que mi suerte os ruega), vuestro llanto.

Habiendo obtenido vientos favorables, nuestra nave desde Oriente surcaba ya las aguas marinas. Aquí iban mi oro, mis esperanzas y, más preciosa que toda brisa, mi esposa y los queridos hijos de mi esposa. Y ya la navehabía recorrido segura la mitad del camino y había indicios ya casi de nuestra salvación, cuando de repente, ¡ah, condición engañosa e inestable del mar!, una cruel tempestad se abatió sobre el mar entero. Al punto se erizó el océano agitado por airadas olas y levanta monstruosas amenazas hacia el cielo. Una ola sepultó la nave e impetuosa ante los soberbios despojos, se alegra de voltear vencedora las riquezas cautivas. A nosotros nos acogió en su seno una lancha cercana, única esperanza en tan gran desgracia. A donde nos empuja el viento, a donde nos arrebata el ímpetu de las olas, allá somos arrastrados como presa destinada a ser devorada por el mar enrabietado.

Tocamos tierra finalmente, pero era tierra salvaje y se demostró más salvaje que las propias olas. Tierra sin cultivar, deforme, carente de recursos, tierra hórrida, por la que apenas se podía marchar a través de desnudas rocas y vastas montañas. Así pues, habiéndome ceñido mis armas, que el agua había respetado, exploro como huésped náufrago la tierra desierta, por ver si algún árbol que me encontrara en el selvático terreno me proporciona algún alimento para mi esposa y mis hijos, que gemían.

\footnotetext{
${ }^{10}$ Las traducciones que figuran en este trabajo son propias.
} 
He aquí que una gente de mirada torva se precipita sobre mí y con aspecto de fieras amenazándome con cruel muerte me ordena deponer las armas. Tres veces quise arrojarme solo en medio de los enemigos y sufrir voluntariamente la deseada muerte. Tres veces mi mano ultrajada abandonó su intento a la mitad. Venció el amor y, vencedor, me ordena deponer las armas. Claro está, mi esposa y mis hijos tendidos en la playa refrenaban como tiernas cadenas mi ánimo. Caen de mis manos las armas. Armado tan solo con mi rostro bañado en lágrimas, pido con aspecto suplicante algo de alimento. Pero ellos cruelmente se burlaron de mis súplicas y se retiraron sin escucharme ante mi precipitada fuga. Por tanto, triste, privado de todo recurso, despojado, desarmado y enloquecido me dirijo de nuevo con infaustos pasos a la playa donde estaban mis seres queridos. ¡Ay de mí! ¿Qué veo? La sombría playa pone ante mis ojos a mis hijos moribundos.

¡Ay! ¡Qué sentimientos albergué entonces en mi corazón! Los que tiene quien vive con la mitad de su cuerpo. Solo mi esposa sobrevivía, tras la muerte de los hijos. A esta se la llevó también el hambre unida al dolor. ¿Qué haré, padre sin hijos, esposo sin esposa, única parte sobreviviente de mis compañeros? Mi sustento son las lágrimas, mi lecho la playa desnuda y mi voz invoca gimiendo tristemente la muerte, la muerte una y otra vez. Vosotros, amigos, realizad mis funerales. Formulad, por favor, fúnebres súplicas por mí. Habiendo sufrido tantas heridas mortales en mis miembros, si no muero de hambre, moriré con toda seguridad de dolor.

\section{LA HISTORIA}

El texto de Iriarte tiene como punto de partida la historia de un naufragio famoso ocurrido a mediados del siglo XVI, el del portugués Manuel de Sousa Sepúlveda que había estado al frente del castillo Diense en la India. Deseando volver a su patria, embarcó en Cochín, en la costa sur de ese país, el 3 de febrero de $1552^{11}$. Le acompañaban su familia -su esposa Leonor de Sá, dos hijos pequeños que había tenido en su matrimonio y otro de unos diez o doce años hijo de una relación anterior de Sousa-, algunos nobles, los marineros y numerosos sirvientes y esclavos. Llevaban un pesado cargamento de especias y otras mercancías para negociar en Lisboa. Tras dos meses de navegación, el barco fue destruido por una tempestad cerca del cabo de Buena Esperanza. La mayor parte de los tripulantes consigue salvarse y llegar a tierra. Desde aquí pretenden acercarse hasta el río Lorenço Marques y encontrar allí algún navío portugués que los llevara de regreso a su país. Las penalidades del camino van diezmando al grupo. El hijo mayor de Sousa es uno de los primeros en fallecer. Encuentran un reyezuelo afable, bien dispuesto hacia los portugueses, que los acoge muy afectuosamente y les avisa de los peligros en caso de seguir adelante.

${ }^{11}$ Emmanuel Sosa, cognomento Sepulueda, qui Diensi (vti memoratum est) praefuerat olim arci, vir opulentus ac splendidus, ducta in matrimonium Eleonora Garziae Salae tum Praetoris flia, tactus desiderio patriae pressam diuitiis rostratam excelsam Cocini conscendit (Maffei, 1590: 721). 
Pero ni las súplicas ni las advertencias sirven de nada, pues Sousa sospecha la existencia de un engaño.

Durante su marcha les salen al encuentro unos negros. Los portugueses, en un primer momento, creyendo que se avecinaba un combate, aprestan las armas y preparan lo que les quedaba de fuerzas para rechazar a los bandoleros. Los nativos simulan intenciones amistosas y los invitan a su ciudad. Sousa, que había rehusado prestar crédito al reyezuelo anterior que lo invitaba amistosamente, se puso en sus manos.

Primero los separan en distintas aldeas y luego les hacen entregar las armas. El rey de estos territorios que había acogido a Sousa con simulada humanidad se quita finalmente la máscara y ordena que lo ataquen y lo expulsen. No fue este el final de sus desgracias. Una nueva tropa de negros ataca la compañía de Sousa y los despoja de sus ropas ${ }^{12}$. El padre se retira a un bosque próximo buscando cualquier clase de alimento. Al volver de allí descubre los cadáveres de Leonor y de los hijos. Después de sepultarlos, no volvió a pronunciar palabra y finalmente se refugió en las selvas ${ }^{13}$. Allí se cree que fue despedazado por las fieras y nunca se lo volvió a ver.

Los numerosos naufragios que barcos portugueses padecían en la ruta de la India dieron lugar en Portugal, en los siglos XVI y XVII, a una literatura popular que recogía en pliegos de cordel los desastres más conocidos ${ }^{14}$.

El relato pormenorizado de los acontecimientos se encontraba en el libro XVI de las Historiarum Indicarum (1590:712-763) de Giovanni Pietro Maffei (1533-1603), que narra los hechos, aunque prescindiendo del hijo ilegítimo; de esta versión provienen los tratamientos neolatinos posteriores de la historia. Estos conservan la fraseología de Maffei e incrementan su tono moralizante. El tema es utilizado por Jakob Bidermann (1578-1639) en el libro II de sus Heroum Epistolae (1634: 87-96), que es el antecedente más directo del texto de Iriarte. Nicolás Avancini (1611-1686) se sirvió del tema como argumento de una de sus tragedias en latín, Ambitio siue Sosa Naufragus $(1655: 1-71)^{15}$. El argumento pasó a formar parte del repertorio de historias de las obras moralizantes. Fue incluido, por ejemplo, en el Concionator historicus (1680: 641-658) del padre Michael Pexenfelder (1613-1685), cuyo relato reutiliza, al igual que ocurre

${ }^{12}$ Tum demum sensere Sosa comitesque, quam stulte sese inermes ignotae ac barbarae fidei credidissent. Neque hic finis miseriarum fuit. nanque dum inopes consilii, solutis ordinibus, nullo rectore, nullo signifero, passim incerto errant gradu; noua repente Aethiopum manus, praeacutis armata sudibus, in Sosae manipulum inuadit (Maffei, 1590: 729-730).

${ }^{13}$ Postridie eodem pabulandi functus officio, coniugem vna cum filio exanimem reperit, \& lamentabili circum vociferatione complorantes ancillas. Hisce confestim summotis, in dextram iacentis manum aliquandiu reclinato capite incubuit: dein, iisdem adiuuantibus ancillis cadauer vtrumque sepeliit nibil vnquam effatus. Postremo sese iterum abdit in syluas. ibi laniatum a feris putant (Maffei, 1590: 731).

${ }_{14}$ Este tipo de literatura se recoge ya en el XVIII en la obra de Bernardo Gomes de Brito, que recopila en su Historia Trágico-Marítima (1735 y 1736), publicada en dos volúmenes, doce relatos de naufragios. El primero de los relatos es el de Manuel de Sousa (1735: 1-38).

${ }^{15}$ Sobre la representación de esta tragedia en 1643 puede verse el trabajo de Valentin (1977). 
en otros casos, las mismas palabras de Maffei, aunque añadiendo numerosos comentarios que glosan los aspectos morales de la historia y acentuando de este modo el tono moralizante que ya se encontraba en el original.

Fuera de la literatura neolatina, en 1594 el portugués Jerónimo Corte Real publicó un poema de más de 10000 versos titulado Naufrágio de Sepúlveda. En la silva III del Laurel de Apolo de Lope de Vega (1630) se menciona el naufragio, la muerte de Leonor abrazada a sus dos hijos y la locura de Sousa como consecuencia de la desgracia (vv. 16-35).

Tirso de Molina en Escarmientos para el cuerdo (1636) reconstruye fielmente el contexto histórico. La obra consta de tres actos y es en el tercero cuando se produce la partida. El autor justifica el cruel desenlace como castigo divino por los pecados de Sousa, envuelto en un triángulo amoroso. Tirso atenúa la tragedia final haciendo que sea un marinero el encargado de narrar los acontecimientos.

En la comedia Don Manuel de Sosa y naufragio prodigioso, y del príncipe trocado, atribuida a Lope, desaparecen los personajes históricos y tras el naufragio llegan a una isla habitada por indios. La obra no acaba con la muerte de Leonor y sus hijos. Pese a todo en ella se encuentran los ecos del relato del naufragio. Aquí Sousa no es el responsable del castigo, sino que todo se debe a la fatalidad ${ }^{16}$.

Francisco de Contreras, amigo y admirador de Lope de Vega, le dedica la Nave Trágica de la India de Portugal (1624), en la que vemos la combinación de la mitología con la historia. Consta de 800 versos repartidos en tres cantos. Dedica los dos primeros cantos a la descripción de la tempestad y el naufragio. El resto de la historia se condensa en el tercero dificultando al lector con frecuencia la comprensión ${ }^{17}$.

A pesar de que los autores neolatinos remiten al texto de Maffei y los escritos en español a la literatura de cordel, todos ellos han modificado algún aspecto del relato y le han incrementado la orientación moralizante. Resulta natural el protagonismo que adquieren en las versiones teatrales los hijos. En cambio, la madre, Eleonora, que tiene gran relevancia en las versiones más antiguas del relato y en el teatro español, lo pierde en algunas de las versiones neolatinas.

La esposa tenía en Maffei un papel importante. Desde un primer momento se resalta su origen noble y se habla de ella como causa de la perturbación mental de su marido y como compañera infatigable de sus sufrimientos. Es luego la única que habla contra la decisión de entregar las armas. Una de las razones de la fama de este suceso se basaba precisamente en el episodio en el que la esposa de Sousa, al quitárseles a todos los vestidos, se entierra para proteger su pudor, ocultando el resto de su cuerpo con sus largos cabellos ${ }^{18}$. Oleza (2011).

${ }^{16}$ Sobre el tratamiento del tema en Lope de Vega y en Tirso de Molina se puede consultar Montes (1977).

${ }^{17}$ La relación entre los poemas de F. de Contreras y J. Corte Real puede verse en Ares

${ }^{18}$ En el Symbolum XVIII de Ethyca Symbolica de Pexenfelder se incluye un relato que se centra, en cambio, en este episodio (1675: 89). 
En los textos neolatinos hay también una tendencia a la simplificación temporal del relato. Naturalmente las obras teatrales prescinden de las penurias del viaje por tierra, cuyo carácter pavoroso, asediados por los nativos y por las fieras, resalta, en cambio, Maffei. En el relato de este solo al cuarto mes llegan a la región que constituye su meta, pero no la reconocen y no pueden comunicarse con los nativos a causa del desconocimiento del idioma. En el Concionator historicus de Pexenfelder se omite el episodio del reyezuelo amable, que da una imagen positiva de los nativos, imprimiendo así un sesgo tendencioso a la historia. La simplificación es mayor todavía en el poema de Bidermann, en el que el desastre parece tener lugar inmediatamente después del naufragio.

El poema de Bidermann (1634: 87-96) comienza, como en Iriarte, con la interpelación a los camaradas (vv. 1-4):

Vos ego Sosa meos, o pectora fida, Sodales,

Patria quos tuto seruat Ibera sinu,

Vos ego Memnoniae nauifragus hospes arenae,

Ad mea ferali funera uoce uoco.

A vosotros, corazones fieles, que la patria ibera en su seno mantiene en seguridad, yo, Sousa, náufrago a quien acoge la arena africana, os convoco a mis funerales con la voz de quien está ya cerca de la muerte.

En esta versión la esposa se opone a la entrega de las armas (vv. 151-154):

Omnibus una uiris generosior obstitit uxor, Arma uiri, ingeminans, arma tenete uiri;

Nulla fides hosti; fraus barbara fallet inermes:

Arma cibos nobis, arma retenta, dabant.

Solo mi esposa se opuso, más animosa que todos los varones, repitiendo: "Retened las armas, hombres, retenedlas. Ninguna fe posee el enemigo; la perfidia bárbara nos defraudará una vez desarmados. Las armas, las armas que reteníamos, nos proporcionaban la comida".

Y también aquí, como en el relato original, se entierra a sí misma, para evitar que su pudor sufra (vv. 169-170):

Abdita se Coniux sabulo defodit in alto,

Quaeque nequit sabulo condere, crine tegit.

Mi esposa se enterró escondiéndose en lo profundo de la arena y lo que no pudo tapar con la arena lo cubre con sus cabellos.

En el texto de Iriarte se perciben los mismos aspectos que hemos apreciado en las versiones neolatinas de la historia. Como podemos observar por la lista de autores anteriores que se ocuparon del tema, se trata de un argumento reiterado en las obras de autores jesuitas. No nos puede, pues, extrañar que Iriarte haya tenido 
conocimiento del tema durante su formación, ligada precisamente a los jesuitas, ya que en un primer momento estudió en el colegio que la Compañía tenía en la ciudad francesa de Ruan y posteriormente estuvo ocho años en el Colegio Luis el Grande de París.

Muchos de los textos que forman parte de este primer manuscrito en el que se encuentra el poema de Sousa tienen el carácter de ejercicios escolares, con aire artificioso y esa mezcla del enfoque poético y retórico tan característica de la enseñanza de los jesuitas. Son similares a los tradicionales progymnasmata retóricos (o los modernos ejercicios de redacción), pero en verso. Están muy próximos a los textos que podemos encontrar en las sucesivas ediciones de la Bibliotheca Rhetorum, praecepta et exempla complectens, quae ad oratoriam et poeticam facultatem pertinent de G. F. Le Jay (1657-1734). El texto que nos ocupa es un ejemplo más del tipo de composiciones iniciales de los primeros años de formación del humanista canario.

$\mathrm{Al}$ igual que en la versión de Bidermann, el texto adopta en Iriarte forma epistolar, en la que el protagonista se dirige a sus amigos ausentes. También coincide con Bidermann en la simplificación temporal de los acontecimientos haciendo que el ataque se produzca inmediatamente después del naufragio. Como en las versiones teatrales la esposa ha perdido protagonismo y no se habla del episodio del enterramiento para proteger el pudor, que sí se encuentra, por el contrario, en Bidermann. El texto se centra en los patéticos e inútiles intentos del personaje de buscar comida para sus hijos. El poema es, por otra parte, mucho más breve que el de Bidermann.

\section{LA CUESTIÓN DEL GÉNERO}

¿Cómo hemos de entender el texto de Iriarte desde el punto de vista literario? Para conocer las implicaciones literarias de una obra determinada es fundamental comprender el sistema genérico subyacente a dicha obra. El texto que nos ocupa es una epístola poética. Debemos, pues, estudiarlo a la luz de la concepción que tenía esta época de la elegía y de la heroida.

En los tratamientos teóricos del humanismo la heroida se presenta con frecuencia como un apartado más en el capítulo dedicado a la elegía. Pero, si la relación de ambas formas es indiscutible, existen, por otra parte, varios aspectos en los que la heroida se singulariza, lo que le confiere una identidad propia dentro de la enorme variedad temática del género elegíaco ${ }^{19}$.

En la literatura latina la elegía se concebía a partir de criterios formales, el metro y la extensión; en las lenguas modernas, en las que la literatura neolatina convive con la escrita en lengua vulgar, la forma métrica ya no puede definir el género, que

${ }^{19}$ Sobre la tradición de la heroida véase el libro de Dörrie (1968). 
pasa a ser concebido de acuerdo con un criterio temático. En las poéticas clasicistas la elegía es vista, a partir de la etimología y del motivo de la flebilis elegia de los autores clásicos, como un poema de queja, fuera esta amorosa o fúnebre, descripción que difícilmente responde a la amplitud del género en Roma. El conflicto entre esta concepción y la enorme libertad temática, heredada de la literatura clásica, que caracterizaba la práctica poética, era salvado por las preceptivas teóricas diferenciando generalmente una forma genuina del género frente a una concepción menos rigurosa. Las Heroidas de Ovidio, lamentos de heroínas abandonadas, eran, en cambio, fácilmente comprensibles desde este tipo de planteamiento.

En este sentido el poema de Iriarte además de conservar la forma métrica de la elegía clásica, pues está escrito en dísticos elegíacos, se ajusta perfectamente a la concepción moderna del género de la elegía.

Como en el caso de la lírica, las poéticas clasicistas se enfrentaban a la cuestión de si la elegía debía considerarse auténtica "poesía”, al definirse esta, no por el verso, sino por la imitación. La concepción de la elegía como imitación implicaba, por otra parte, que la diferencia entre la elegía personal y la heroida se atenuaba aun más. Nuestro Cascales (1563-1642) definía la elegía como "imitación de una perfecta acción lamentable" (1779: 153), y un autor del XVIII, el padre Franz Neumayr (1697-1765), la define, por ejemplo, del siguiente modo (1759: 144): Elegia est carmen imitans affectus personae uehementer commotae uersu impari, \& congruo ad characterem aetatis conditionis ac morum: «La elegía es un poema que imita los afectos de una persona violentamente conmovida en dísticos elegíacos y congruentes con el carácter de la edad, la condición y las costumbres». Como ejemplo de elegía utiliza Neumayr la heroida ovidiana de Penélope a Ulises. Y como ejemplo propio de una epístola heroica, no recogida en la monumental obra de Dörrie (1968), la de Séneca moribundo a Nerón.

Después del siglo XVIII, al abandonarse la concepción imitativa de la lírica y de la elegía, esta última, percibida tradicionalmente como poesía de sentimientos, quedará fácilmente englobada dentro del género de la lírica, entendida ahora como expresión del yo poético. La elegía será, de este modo, considerada como una modalidad más concreta de la lírica y la diferencia con la heroida tenderá, por consiguiente, a incrementarse.

Si la concepción imitativa de la lírica y la elegía facilitaba la inclusión de la heroida dentro de la elegía, otros rasgos permitían, por otra parte, singularizar la heroida como género. La elegía se entendía, por ejemplo, como más extensa que el epigrama o el soneto, y menos que los géneros más elevados. Se acepta, sin embargo, habitualmente $-\mathrm{y}$ así lo testimonia también la práctica de los propios escritoresque la extensión de la heroida puede ser algo mayor. Con respecto al tono, la elegía se caracterizaría también por un estilo menos elevado que la épica o la tragedia. Según la doctrina común de la poética clásica, el estilo apropiado para la elegía es el medio o incluso el ínfimo, siempre menos elevado que el de la epopeya. At res sublimes et maiestas heroica ab elegia excluduntur: quapropter Horatius Elegos nocat exiguos, "Los temas sublimes y la majestad heroica están excluidos de la elegía, por lo cual Horacio llama a los dísticos elegíacos "exiguos" ", dice el padre Le Jay en su Bibliotheca Rhetorum a propósito de la elegía (1726: 102). 
Pero la heroida y las otras formas de elegía "objetiva", como algunos poemas del libro IV de Propercio o los Fastos ovidianos, supondrían, según los tratadistas, una excepción en que el género se elevaría "por encima de sí mismo". Marmontel en su influyente tratado Poetique françoise (1763: 504-523) diferenciará distintos tipos dentro de la elegía, de modo que la heroida sería simplemente un tipo de la "elegía patética".

Como ya hemos visto, el tema del naufragio de Sousa del que se ocupa el texto de Iriarte había sido objeto de tratamientos teatrales previos. La concepción de la elegía como imitación de los sentimientos la acerca a un monólogo dramático. Tanto la elegía como la heroida se ven así aproximadas a las obras dramáticas. A partir del XVIII serán muchos los autores que resalten la relación de la heroida, entendida como epístola heroica y, por tanto, de tono más elevado que la elegía, con la epopeya y la tragedia.

De este modo, el dogma de la concentración dramática, que las reglas derivadas de Aristóteles habían convertido en normativa para la poesía en general, puede aplicarse fácilmente al género. El autor debería concentrar la acción de una tragedia entera en los límites de la heroida. Significaría también elegir un personaje determinado como foco de percepción del relato.

El poema de Iriarte debe situarse a comienzos del siglo XVIII ${ }^{20}$. En el transcurso de ese siglo la heroida va a experimentar una floración pasajera, pero intensa, que pone de manifiesto las tendencias que hemos podido observar y a que daba lugar su integración dentro del sistema genérico de las formas poéticas tradicionales. No faltarán los autores que, de acuerdo con la concepción del género como epístola heroica, defiendan la ampliación de la temática que no se limita ya al amor. J. F. de La Harpe (17391803) será, por ejemplo, un firme partidario de la variedad temática y así lo reflejan claramente sus epístolas con personajes tomados de la historia romana, que concuerdan perfectamente con los temas romanos de la tragedia de la época (La Harpe, 1771).

La ampliación temática se había iniciado ya en épocas anteriores en la heroida religiosa con la obra Heroidum Christianarum epistolae de Eobanus Hessius (14881540), y había sido continuada por los escritores jesuitas del XVII. Aunque el género se mantenía fiel al tema del amor, este no era ya el amor profano de las heroidas clásicas. Tampoco el destinario debía ser necesariamente la persona amada. En el XVIII

${ }^{20}$ En el año 1713 había marchado a Francia, pues su padre como hijo mayor lo había destinado a recibir una mejor educación. Tras una primera estancia en París, volvería con posterioridad para continuar allí sus estudios durante los últimos ocho años de su estancia en ese país. En 1723 le pide su padre que regrese a Tenerife, aconsejándole que pase primero por Londres, donde estuvo poco tiempo porque recibió la noticia de la enfermedad de su padre. Cuando llegó a Tenerife su padre ya había fallecido y a finales de 1724 decidió marchar a Madrid. Por tanto, si el poema se encuentra en el manuscrito que lleva como título Versos latinos míos de cuando yo estudiaba en París, Iriarte debió escribirlo antes de 1724. 
basta con la existencia de un personaje central, ya sea el emisor o el receptor de la epístola, ligado a una gran pasión o que haya sufrido un notable cambio de fortuna ${ }^{21}$.

\section{RETÓRICA Y POESÍA}

Una problemática, común en realidad a diversos géneros, pero que en la epístola poética presenta vertientes específicas, es el conflicto entre el nivel retórico y el nivel poético de la obra, o, lo que es lo mismo, entre la situación comunicativa presupuesta por el universo de ficción del texto y el nivel comunicativo en que el texto se dirige al lector. La heroida suele ser definida con frecuencia como un género mixto en el que la epístola convive con la elegía. Pero ambos géneros no se encuentran en realidad al mismo nivel. La epístola implica una finalidad práctica que nada tiene que ver con la significación literaria del texto. La epístola salva distancias, mientras que la elegía tiende a ponerlas de manifiesto. Otra vertiente de la misma problemática puede observarse en la opinión moderna que pretende hacer de la heroida una mera suasoria.

La definición que hace de la elegía un poema que expresa ante todo los sentimientos y los caracteres aproximaba la heroida -y la elegía - al ejercicio retórico de la etopeya. Este enfoque de la poesía, similar a los que Iriarte tuvo ocasión sin duda de conocer durante su etapa de formación juvenil en Francia, suponía un planteamiento retórico de las obras poéticas.

El tratamiento teórico que hace, por ejemplo, el padre F. Neumayr de la composición de la elegía es totalmente retórico (1759: 144-146):

Elegia est carmen imitans affectus personae uehementer commotae, uersu impari, $\&$ congruo ad characterem aetatis, conditionis, ac morum. Qui Ethopaeiae, siue descriptionibus personae iam amantis, iam irascentis, iam trepidantis, desperantis \&c. [...] assueuit, facile Elegiam conformem characteri conficiet, praecipue si (quod supra monui) praeter affectus causam, \& occasionem quae semper in opinione boni aut mali siue praesentis siue imminentis aut imaginarii etiam, ac mere apparentis consistit, insuper effectus illius affectus inspicias [...]. Praxin docebit resolutio nonnullarum ex Epistolis Ouidii. Prima, quam Penelope Ulyssi scribit, exemplum esto. Argumentum, \& scopus est Significatio desiderii de reditu uiri. Medium, expositio causarum, cur desideret. Propositio. Cupio, ut redeas. Inuentio. Quia nulla est causa morae, multa autem celeritatis. Ex his fit syllogismus totius Elegiam compendium: uir debet redire ad uxorem quando iusta causa urget, \& causa morae cessauit,

\footnotetext{
${ }^{21}$ Merian ofrece la siguiente definición (1783: 506):
}

Je définirais l'Héroïde, une épître, ou une élégie dramatique, dans laquelle un personnage célèbre par une passion malheureuse, ou par un grand revers de fortune, donne essor aux mouvemens dont son âme est agitée. 
nam uxoris sine uiro uita est plena taedio, \& sollicitudine. Atqui cessauit causa morae, nam Troia periit, \& alii Duces redierunt: insuper causae graues urgent, nam proci, tanquam si tu iam obiisses, postulant, ut ducam uirum alium: ergo debes redire, $\&$ hoc est, quod per quidquid est charum, te oro.

La elegía es un poema que imita los afectos de una persona violentamente conmovida en dísticos elegíacos y congruentes con el carácter de la edad, la condición y las costumbres. Quien tiene la costumbre de la etopeya, o descripciones de la persona, ya del amante, ya del que monta en cólera, ya del que tiembla de miedo, del desesperado, etc. [...] fácilmente creará una elegía conforme al carácter, especialmente si (lo que te aconsejé más arriba) tienes en cuenta, además de los afectos, la causa y la ocasión, que siempre consiste en la opinión sobre lo bueno o lo malo, presente o inminente o imaginario incluso y meramente aparente [...].

La práctica te enseñará la consideración pormenorizada de algunas de las epístolas de Ovidio. Sirva de ejemplo la primera, que Penélope escribió a Ulises. El argumento y objetivo es la significación de la añoranza por la vuelta del marido. El planteamiento es la exposición de las causas de su añoranza. La proposición: "deseo que vuelvas". La invención: no hay ningún motivo para el retraso y muchos para darse prisa. A partir de tales planteamientos se hace un silogismo que compendia toda la elegía: el marido debe regresar junto a su esposa cuando una causa justa apremia y desapareció toda causa de demora, pues la vida de una esposa sin su marido está llena de tedio y preocupación. Ahora bien, toda causa de demora ha desaparecido, pues Troya ha perecido y los otros caudillos han regresado. Además motivos graves apremian, pues los pretendientes, como si tú ya hubieras muerto, exigen que me case con otro marido; por tanto, debes regresar y esto es lo que, por todo lo que te es querido, te suplico.

Neumayr subraya la relación entre elegía y etopeya. Los rétores antiguos distinguían dos tipos de etopeya o prosopopeya: ética y patética. Las primeras se basan en los caracteres, las segundas en la emoción. En el caso de las etopeyas patéticas o emocionales, lo esencial viene dado por el patetismo de la situación (un padre que se lamenta, por ejemplo, por la muerte de su hijo); en el caso de las éticas (caracterizantes) se trata ante todo de ver cómo reacciona el personaje al ser puesto a prueba por las circunstancias. De este modo, los pensamientos expresados en su discurso se convierten en signos que remiten a su condición social, su psicología, etc. En los textos literarios ambos aspectos (el ético y el patético) conviven habitualmente.

\section{HEROIDAS LATINAS Y ELEGÍAS OBJETIVAS}

La proximidad entre una concepción imitativa de la elegía y la heroida explica que a veces encontremos en esta época composiciones poéticas calificadas como elegías y que nosotros nos inclinaríamos más bien a clasificar como heroidas y a la inversa.

Entre los textos que ejemplifican el género de la elegía en el segundo tomo de la Bibliotheca Rhetorum del padre Le Jay, en el apartado Carmina miscellanea, consagrado a la elegía y a la lírica, figura un poema titulado Paulinae desiderium. Cum Maritus ipsius Seneca morte damnatus esset (1726: 316-317; 1747: 648). Paulina, 
al ser condenado su esposo, piensa en suicidarse. El texto, que lleva el encabezamiento de Elegia, desarrolla los tópicos del amor matrimonial y la queja contra el tirano con el consabido "en un solo crimen dos víctimas" y se dirige bien al propio Séneca, bien a Nerón. La proximidad con el género de la heroida resulta evidente ${ }^{22}$.

De modo similar, F. Neumayr incluye en su Idea Poeseos (1759: 147-163) una larga elegía que se presenta como una carta escrita y dirigida a Nerón, en los últimos momentos de la vida de Séneca (Seneca Moriens Neroni).

En su planteamiento de la elegía se hace hincapié en el aspecto patético. El tema elegido corresponde a la ampliación temática de la epístola heroica y relaciona el poema con los temas romanos de la tragedia contemporánea, algo nada sorprendente en un escritor que es conocido por la posteridad más por sus creaciones teatrales que por sus tratados teóricos. Séneca es un personaje trágico por excelencia ${ }^{23}$.

Tampoco resulta sorprendente que la relación maestro - discípulo sea uno de los ejes temáticos del texto. Esta elegía constituye la última enseñanza del maestro, una lección negativa, inversa a la positiva que le ha dado en el pasado y que coincide con la que el autor pretende hacer llegar a su lector.

La ampliación temática no acaba de romper, sin embargo, del todo con el código genérico, para el que el amor es el tema central. La relación que ha unido a Séneca con su discípulo puede considerarse una forma de amor y su muerte se presenta como la culminación de una serie de crímenes, contra el hermano, la madre y la propia patria, que atentan contra la pietas.

\section{A MODO DE CONCLUSIÓN}

El poema de Iriarte tiene todo el aspecto de ser un ejercicio escolar relacionado con su etapa de formación en Francia. Tal cosa puede deducirse de su inclusión

${ }^{22}$ En realidad todos los textos que en la obra de Le Jay conforman la sección dedicada a la elegía son ajenos a lo personal. Así, en el poema Anima poenitens (1726: 313; 1747: 646) el pecador se dirige a Dios mostrando su arrepentimiento; en Anima inferis ignibus damnata. Ad Amicum olim suum adhuc viventem (1726: 314; 1747: 646-647) un condenado se dirige a un amigo todavía vivo. El poema Filius ad patrem. Cum exulare iussus inconsulto patre revertisset, dedicado al tema del hijo pródigo (1726: 317; 1747: 649), está escrito en tercera persona y con forma de epístola. En el poema paródico Poetae luctus amissa crumena (1726: 315; 1747: 647-648) el poeta se queja por haber perdido la bolsa. Todos ellos testimonian la idea de la elegía como poesía que tiene por tema la lamentación, así como la concepción imitativa de la elegía, que no permite en realidad diferenciar entre elegía objetiva y personal. El poema sobre el hijo pródigo puede perfectamente considerarse una heroida, salvo por tratarse de personajes desconocidos, que corresponden a las figuras arquetípicas de la relación paterno-filial. La inclusión en el mismo apartado de elegías y odas muestra, por otra parte, la proximidad percibida por el autor entre elegía y lírica.

${ }^{23}$ También el tema de José (Josephus Jacobum ad se in Aegyptum vocat), propuesto por el autor para la imitación por parte de los alumnos de la epístola de Penélope a Ulises, muestra el mismo gusto por la ampliación temática del módulo genérico original y la proximidad a lo teatral, pues el tema de José y sus hermanos era característico de la tragedia sacra neolatina. 
en los manuscritos del autor entre los textos correspondientes a esta época. Esta hipótesis se ve igualmente confirmada tanto por el tema como por el modo en que el autor ha conformado el argumento. Había sido objeto de diversos tratamientos previos por parte de escritores jesuitas. Es, pues, verosímil que Iriarte haya tenido noticia de la historia en esta etapa de su vida ligada precisamente a la Orden. Su versión está muy alejada del texto de Maffei, a diferencia de las restantes escritas en latín, en las que suele haber ecos verbales del relato original. ¿Conocía realmente de primera mano las Historiarum Indicarum de Maffei?

El tema del texto responde perfectamente a una idea de la elegía como género ligado a los sentimientos y especialmente al lamento. La concepción de la elegía como imitación de los sentimientos ha facilitado la aproximación entre elegía y epístola poética. El poema del jesuita Bidermann, precedente directo del de Iriarte, muestra, por otra parte, cómo la aplicación de la heroida al ámbito religioso ha permitido a la epístola heroica liberarse de las limitaciones temáticas tradicionales. El término heroum en el título de la obra de Bidermann tiene implicaciones genéricas.

Iriarte en su tratamiento ha prescindido del papel de la esposa, que, en cuanto entrañaba un punto de vista femenino, contrapuesto al de su marido, suponía una oportunidad para enlazar con la tradición de la heroida. Por otra parte, ha eliminado igualmente los aspectos que podían conectar de forma más clara el argumento con la temática heroica y su texto es mucho más breve que el de Bidermann. Insiste sobre todo en el drama familiar del padre incapaz de auxiliar a los hijos.

RECIBIDO: septiembre 2018; ACEPTADO: diciembre 2018.

\section{BIBLIOGRAFÍA}

Manuscritos DEL "Fondo Iriarte"

B99-A-10(2): Noticia de la vida y literatura de D. Juan de Iriarte y documentos y cartas relativos a su persona y empleos y estudios.

B102-A-14: Versos latinos míos de cuando yo estudiaba en Paris.

\section{EsTUDIOS}

Ares Montes, J. (1977): "Francisco de Contreras y el naufragio de Sepúlveda", Revista de Filología Española LIX (1/4): 256-277.

Avancini, N. (1655): Poesis dramatica, I, Typis M. Cosmerovii, Viennae Austriae.

BidermanN, J. (1634): Heroum Epistolae: ad Romanum exemplar recusae, Formis Leysserianis, Monachii.

Blasco Pascual, F. J. (2011): Poética de la escritura. El taller del poeta. Ensayo de crítica genética (Juan Ramón Jiménez, Francisco Pino y Claudio Rodríguez), Cátedra Miguel Delibes, Valladolid.

Cascales, F. (1779): Tablas poéticas del Licenciado Don Francisco Cascales, por Don Antonio de Sancha, Madrid.

Corte Real, J. (1783): "Naufragio e lastimoso successo da perdiçaõ de Manoel de Sousa de Sepúlveda e Dona Lionor de Sá, sua mulher e filhos”, na Typografía Rollandiana, Lisboa. 
COTARelo y Mori, E. (1897): Iriarte y su época, Sucesores de Rivadeneira, Madrid.

CuYÁs de Torres, M. E. (1989): “Juan de Iriarte: ¿Traductor de Marcial o poeta original?”, en Actas del VII Congreso Español de Estudios Clásicos, t. III, Universidad Complutense, Madrid, pp. 461-467.

CuYÁs de TORRES, M. E. (1992): “La Gramática Latina de Juan de Iriarte”, Excerpta philologica 2: 133-148.

CuYÁs de Torres, M. E. (1996a): "Estudio de las figuras en la Gramática de Juan de Iriarte”, Myrtia 11: 33-46.

CUYÁS DE TORRES, M. E. (1996b): "Una cuestión de sintaxis: ¿Qué pensaba Juan de Iriarte del ablativo absoluto”, Cuad. Filol. Clás. Estud. Lat. 10: 237-253.

Cuyás de Torres, M. E. (2002): “Casos y preposiciones en Juan de Iriarte”, enStudia Humanitatis in honorem Antonio Cabrera Perera, Universidad, Las Palmas de Gran Canaria, pp. 427-438.

CUYÁs de TORREs, M. E. (2005a): "Juan de Iriarte uersus Nebrija: a propósito del participio pasivo castellano en locuciones con valor temporal”, Cuad. Filol. Clás. Estud. Lat. 25: 123-140.

CUYÁS DE TORRES, M. E. (2005b): "El participio pasivo castellano en Juan de Iriarte: una aproximación”, en F. J. QueVEDO GarCía et alii (coords.), Con quien tanto quería. Estudios en homenaje a María del Prado Escobar Bonilla, Universidad, Las Palmas de Gran Canaria, pp. 121-126.

CuYÁs de Torres, M. E. (2009): “La selección de Marcial en el canario Juan de Iriarte”, en M. a D. GARCía de Paso Carrasco y G. Rodríguez Herrera (coords.), Selección, manipulación y uso metaliterario de los autores clásicos, Pórtico Librerías, Zaragoza, pp. 237-270.

CuYÁs de Torres, M. E. (2010): “Epigramas latinos de Juan de Iriarte”, en J. LuQUE Moreno et alii (coords.), Dulces Camenae. Poética y poesía Latinas, Universidad de Granada, Granada, pp. 1101-1108.

CuYÁs de TORres, M. E. (2014): "Las inscripciones latinas de Juan de Iriarte", en M. a T. CALlejAS BERDONÉs et alii (eds.), Manipulus studiorum: en recuerdo de la profesora Ana María Aldama Roy, Escolar y Mayo, Madrid, pp. 255-263.

De Andrés, G. (1986): “El bibliotecario D. Juan de Iriarte”, en Homenaje a Luis Morales Oliver, Fundación Universidad Española, Madrid, pp. 587-606.

De Biasi, P. M. - WassenaAr, I. (1996): "What is a Literary Draft? Toward a Functional Typology of Genetic Documentation", Yale French Studies 89: 26-58.

De Contreras, F. (1624): Nave trágica de la India de Portugal, por Luis Sánchez, Madrid.

DÖRRIE, H. (1968): Der heroische Brief. Bestandsaufnahme, Geschichte, Kritik einer humanistisch-barocken Literaturgattung, Walter de Gruyter \& Co, Berlin.

GETE, O. (1999): "Juan de Iriarte, traductor de refranes", en F. LAFARGA (ed.), La traducción en España (1750-1830). Lengua, Literatura, Cultura, Universitat de Lleida, Lleida, pp. 245-252.

GOMES DE BRITO, B. (1735): "Relação da muy notável perda do galeão grande S. João, em que se contão os grandes trabalhos e lastimosas cousas que acontecerão ao capitão Manoel de Sousa Sepúlveda e o lamentável fim que elle e sua mulher e filhos, e toda a mais gente, houverão na Terra do Natal, onde se perderão a 24 de Junho de 1552", en Historia Trágico-Marítima, I, na Officina da Congregaçaô do Oratorio, Lisboa, pp. 1-38.

Hernández GonZÁlez, C. (1988-1989): "Reparos de Juan de Iriarte al Diccionario de autoridades", Estudios de lingüistica: E.L.U.A. 5: 201-206.

Hernández GonZÁlez, C. (1996): "Observaciones ortográficas de Juan de Iriarte”, en J. CheCA Beltrán, y J. Álvarez Barrientos (coords.), El siglo que llaman ilustrado: Homenaje a Francisco Aguilar Piñal, CSIC, Madrid, pp. 513-520. 
IrIARTe, J. DE (1769): Regiae Bibliothecae Matritensis Codices Graeci Mss., e Typographia Antonii Pérez de Soto, Matriti.

IRIARTE, J. DE (1771): Gramática latina, escrita con nuevo método y nuevas observaciones, en verso castellano con su explicación en prosa, en la imprenta de Pedro Marín, Madrid.

IRIARTE, J. DE (1774): Obras sueltas de D. Juan de Iriarte, publicadas en obsequio de la literatura a expensas de varios caballeros amantes del ingenio y del mérito, 2 vol., en la imprenta de D. Francisco Manuel de Mena, Madrid.

LA Harpe, J. F. DE (1771): "Essai sur l'Héroïde", en Collection d'Hérö̈des et Pièces Fugitives de divers auteurs, t. VI, en Foire, Liege et Leipsic, pp. 51-59.

LE JAY, G. F. (1726): Bibliotheca Rhetorum, praecepta et exempla complectens, quae ad oratoriam et poeticam facultatem pertinent (auctore P. G. F. Le Jay, S. J.). In multis emendavit et ad justiorem normam revocavit J.A. Amar. Pars posterior. Ars Poetica, sumptibus Joan. Andreae de la Haye, Typis Mariae Magdalenae Riedlin, Parisiis.

LE JAY, G. F. (1747): Bibliotheca Rhetorum, praecepta et exempla complectens, quae ad oratoriam et poeticam facultatem pertinent (auctore P. G. F. Le Jay, S. J.). Pars posterior. Ars Poetica, ex Typographia Balleoniana, Venetiis.

Lope De VegA, F. (1630): Laurel de Apolo, por Juan Gonçalez, Madrid.

MaffeI, G. P. (1590): Ioan. Petri Maffei Bergomatis, Historiarum Indicarum, libri XVI, In officina Bircmannica, sumptibus Arnoldi Mylii, Coloniae Agrippinae.

Marmontel, M. (1763): Poetique françoise, t. II, Chez Lesclapart, Paris.

Merian, M. (1783): "Comment les sciences influent dans la poësie”, en Nouveaux mémoires de L'Académie Royale des Sciences et Belles-Lettres, imprimé chez George Jacques Decker, Berlin, pp. 499-533.

Neumayr, F. (1759): Idea poeseos, sive methodica instructio praeceptis, praxi, et usu artis ad ingeniorum culturam, animorum oblectationem ac morum doctrinam accommodata, sumptibus Ioan. Franc. Xav. Crätz, Augustae et Ingolstadii.

OCHOA, E. DE, (1870): Epistolario Español. Colección de cartas de españoles ilustres antiguos y modernos, t. II, Imprenta y Estenotipia de M. Rivadeneyra, Madrid.

Oleza, J. (2011): “Lope, Tirso, la Historia Trágico-Marítima y la carrera de la India”, en V. MAurYa y M. Insúa (eds.), Actas del I Congreso Ibero-asiático de Hispanistas Siglo de Oro e Hispanismo general, Universidad de Navarra, Pamplona, pp. 481-500.

PeXenfelder, M. (1675): Ethyca Symbolica e fabularum umbris in veritatis lucem varia eruditione, sumptibus Ioannis Wagneri, et Ioannis Hermanni, Typis Sebastiani Rauch, Monachii.

PEXENFELDER, M. (1680): Concionator historicus rariorum eventum exemplis ad instructionem moralem explicatis delectans ac docens, sumptibus Ioannis Wagneri, et Ioannis Hermanni, Typis Sebastiani Rauch, Monachii.

Plaza Picón, F. M. (2004): "Reacción y tradición en la Gramática Latina de Juan de Iriarte", en C. J. CORRALES Zumbado et alii (coords.), Nuevas aportaciones a la historiografia lingüistica: actas del IV Congreso Internacional de la SEHL, vol. 2, Arco Libros, Madrid, pp. 1283-1293.

RUIZ SÁNCHEZ, M.a (2008): “La concepción del género epigramático en la poesía latina de J. de Iriarte”, Myrtia 23: 389-415.

RuIZ SÁnCHEZ, M. a (2014): La obra poética de Juan de Iriarte, Tesis Doctoral, Universidad de Murcia.

RuIZ SÁNCHEZ, M. a (2015a): "La obra poética latina del humanista Juan de Iriarte: un enfoque críticogenético”, Myrtia 30: 229-254. 
Ruiz SÁnchez, M.a (2015b): "La génesis del canon literario. Poemas latinos del círculo de la Fonda de San Sebastián”, en J. M. Baños Baños et alii (eds.), Philologia, Universitas, Vita. Trabajos en honor de Tomás González Rolán, Escolar y Mayo Editores, Madrid, pp. 857-865.

Ruiz SÁNCHEZ, M.a (2015c): "Mayans en los epigramas y epístolas del círculo de los Iriarte”, Tonos digital 29: 1-23.

Ruiz SÁnCHEZ, M.a (2016a): "El ciclo de epigramas latinos de Juan de Iriarte sobre el terremoto de

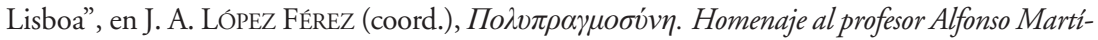
nez Diez, Ediciones Clásicas, Madrid, pp. 669-680.

RuIZ SÁnCHEZ, M. a (2016b): "El tema de la estatua silenciosa: imitación compleja y poesía neolatina”, Cuad. Filol. Clás. Estud. Lat. 36: 107-119.

RuIZ SÁnCHEZ, M.a (2017): “Non sonat arte melos: dos enigmas epigramáticos de Juan de Iriarte”, en

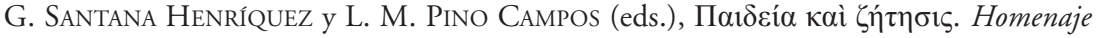
a Marcos Martínez, Ediciones Clásicas, Madrid, pp. 643-652.

Salas Salgado, F. (1998a): "Un opúsculo sobre la traducción en el siglo XVIII español: El comentario de Juan de Iriarte a las 'Obras de Ovidio' traducidas por Diego Suárez de Figueroa”, Revista de Filología de la Universidad de La Laguna 16: 337-357.

Salas Salgado, F. (1998b): "Epigramas latinos sobre tema griego de Juan de Iriarte”, en L. GiL, M. Martínez Pastor y R. M. a Aguilar (eds.), Corolla Complutensis in memoriam J. S. Lasso de la Vega contexta, Editorial Complutense, Madrid, pp. 709-719.

SAlas SAlgado, F. (1999): Humanistas canarios de los siglos XVI a XIX, t. II, Universidad, La Laguna, pp. $140-345$

Salas Salgado, F. (2002): "Observaciones sobre la gestación del poema Hercules Pygmaeorum victor de Juan de Iriarte", Revista de Filología 20: 309-321.

Salas Salgado, F. (2006): “Los primeros poemas en latín de Juan de Iriarte”, Estudios canarios. Anuario del Instituto de Estudios Canarios IL: 117-143.

Santana Henríquez, G. (1990): "El discurso 'Sobre la imperfección de los diccionarios de Juan de Iriarte' y su vigencia actual”, en M.a A. Álvarez Martínez (ed.), Actas del Congreso de la Sociedad Española de Lingüistica, XX Aniversario, vol. 1, Gredos, Madrid, pp. 267-276.

SEMPERE y GuARINOS, J. (1789): Ensayo de una biblioteca española de los mejores escritores del reinado de Carlos III, t. VI, en la Imprenta Real, Madrid.

Serrano, T. (1788): Thomae Serrani Valentini Carminum libri IV. Opus Posthumum. Accedit de eiusdem Serrani vita et litteris Michaelis Garciae Commentarium, ex Typographia Joannis Tomassini, Fulginiae.

Tirso de Molina (1734): Escarmientos para el cuerdo, Privilegio D. Theresa de Guzmán, Madrid.

Tubau, X. (2004): "El Arte que Nebrija no compuso: sobre Juan de Iriarte y su Gramática Latina”, Península 1: 423-454.

Valentin, J. M. (1977): “Zur Wiener Aufführung des Avacinischen Sosa naufragus (1643)”, Humanistica Lovaniensia 26: 220-227.

Viera y Clavijo, J. (1783): Noticias de la historia general de las islas de Canaria, t. IV, en la Imprenta de Blas Román, Madrid. 